\title{
Mechanical Properties of Low Density Polyethylene
}

\author{
Jennifer L. Jordan ${ }^{1}$ Daniel T. Casem ${ }^{2} \cdot$ Jermaine M. Bradley $^{3}$ - Ajmer K. Dwivedi ${ }^{4}$. \\ Eric N. Brown ${ }^{5} \cdot$ Christopher W. Jordan ${ }^{1}$
}

Received: 23 June 2016/Accepted: 1 August 2016/Published online: 10 August 2016

(C) Society for Experimental Mechanics, Inc (outside the US) 2016

\begin{abstract}
The mechanical properties of polymers, particularly as a function of temperature and strain rate, are key for implementation of these materials in design. In this paper, the compressive response of low density polyethylene (LDPE) was investigated across a range of strain rates and temperatures. The mechanical response was found to be temperature and strain rate dependent, showing an increase in stress with increasing strain rate or decreasing temperature. A single linear dependence was observed for flow stress on temperature and log strain rate over the full range of conditions investigated. The temperature and strain rate data were mapped using the method developed by Siviour et al. based on time-temperature superposition using a single mapping parameter indicating that there are no phase transitions over the rates and temperatures investigated. Taylor impact experiments were conducted showing a double deformation zone and yield strength measurements in agreement with compression experiments.
\end{abstract}

Keywords Low density polyethylene · Polymer · High strain rate Taylor test Split Hopkinson pressure bar

Jennifer L. Jordan

jennifer.jordan.6@us.af.mil

1 Air Force Office of Scientific Research, Arlington, VA 22203, USA

2 U.S. Army Research Laboratory, Aberdeen Proving Ground, MD 21005, USA

3 Survice Engineering Company, Belcamp, MD 21017, USA

4 Team Bowhead, Belcamp, MD 21017, USA

5 Los Alamos National Laboratory, Los Alamos, NM 87545, USA

\section{Introduction}

Polyethylene (PE) is a widely used plastic with tailorable properties based on molecular conformation [1-5], with applications ranging from film packaging and electrical insulation to containers and piping. PE is characterized primarily based on density and the degree of molecule branching, as shown in Table 1. Low density polyethylene (LDPE) is a tough and flexible polymer characterized by long branches that do not pack well into crystallites. As the chains become more linear, such as in high density polyethylene (HDPE), the molecules are able to pack more closely. Ultra-high molecular weight polyethylene (UHMWPE) has long, linear chains that are able to carry load along the polymer backbone. Finally, crosslinked polyethylene (PEX) has crosslinked bonds that improve the high temperature properties and chemical resistance [6].

The high rate properties of polymers, including timetemperature superposition in these materials, was recently reviewed by Siviour and Jordan [7]. In semi-crystalline materials, like polyethylene and polytetrafluoroethylene, the response of the material depends on molecular conformation and volume fraction of crystallinity, in addition to temperature and strain rate. These materials can be thought of as molecular networks consisting of an amorphous phase containing entangled chains with the randomly oriented crystallite phase acting as physical crosslinks [2-4]. There have been a few studies in the literature which have investigated the high rate mechanical response of varying PE conformations. Brown et al. [6, 8-10] studied the effects of conformation on HDPE, UHMWPE, and PEX across a range of strain rates and temperatures and found that UHMWPE and PEX had very similar behavior that differed noticeably from HDPE. The same materials have also been studied under a range of loading 
Table 1 Polyethylene classification based on density, molecular weight (MW), percent crystallinity (\%Xtal) and degree of molecule branching $[1,6,16]$

\begin{tabular}{|c|c|c|c|c|}
\hline Polymer & Conformation & $\begin{array}{l}\text { Density }(\mathrm{g} / \\
\left.\mathrm{cm}^{3}\right)\end{array}$ & $\begin{array}{l}\mathrm{MW} \\
(\mathrm{g} / \mathrm{mol})\end{array}$ & $\%$ Xtal \\
\hline Low density polyethylene (LDPE) & Long branches do not pack into crystal well & $0.910-0.925$ & & $25-50$ \\
\hline Linear low density polyethylene (LLDPE) & Shorter branches than LDPE & $0.915-0.925$ & & 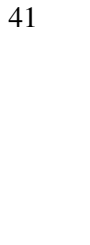 \\
\hline Medium density polyethylene (MDPE) & & $0.926-0.940$ & & \\
\hline High density polyethylene (HDPE) & Linear chains increase crystal packing & $0.941-0.965$ & & $60-80$ \\
\hline $\begin{array}{l}\text { Ultra high molecular weight polyethylene } \\
\text { (UHMWPE) }\end{array}$ & $\begin{array}{l}\text { Long, linear chains effectively transfer load to polymer } \\
\text { backbone }\end{array}$ & $0.930-0.935$ & $3-6 \times 10^{6}$ & 39 \\
\hline Cross-linked polyethylene (PEX) & Crosslinked chains & 0.940 & & 37 \\
\hline
\end{tabular}

conditions including shock loading and dynamic tensile extrusion [11-15]. Similarly, Omar et al. [16] studied LDPE, HDPE, and linear low density polyethylene (LLDPE), in which HDPE exhibited the highest strength in agreement with Brown et al. [6]. However, the actual strength values differed greatly between the two sources, probably due to the almost $20 \%$ difference in crystallinity between the two HDPE materials; the HDPE investigated by Brown et al. [6] with $80.9 \%$ crystallinity exhibited flow stress two to three times higher than reported by Omar et al. [16] for HDPE with $60.99 \%$ crystallinity for a given temperature and strain rate. Brown et al. $[6,8]$ observed a single linear relationship between flow stress and log strain rate and a linear relationship with temperature from room temperature to $-100{ }^{\circ} \mathrm{C}$ [10]. Conversely, Omar et al. [16] observed a non-linear increase in stress with log strain rate albeit based on data at a limited number of strain rates. However, the simple linear relation is also reported by Nakai and Yokoyama [17], who illustrated the dramatic bilinear dependence on log strain rate in many other polymers.

In this study, LDPE was characterized in compression across a range of strain rates and temperatures, using quasistatic loading, split Hopkinson pressure bar loading, and Taylor impact experiments. The degree of crystallinity in the LDPE was determined so that the data could be compared with similar materials in the literature. This study complements the work by Brown et al. [6, 8] on HDPE, UHMWPE, and PEX. The experimental results on LDPE are presented in this paper and discussed in the context of similar PE material conformations.

\section{Experimental Approach}

The LDPE was obtained in plate form from Allied Resinous Products, Inc. The density of the material was measured as $924.2 \mathrm{~kg} / \mathrm{m}^{3}$. The majority of the samples were machined in the through-thickness direction, with a few experiments conducted in the two orthogonal directions.

The LDPE material was characterized using differential scanning calorimetry (DSC) using a TA Instruments DSC Q2000 on approximately $15 \mathrm{mg}$ of material. The test was performed at $10{ }^{\circ} \mathrm{C} / \mathrm{min}$ to $200{ }^{\circ} \mathrm{C}$ to determine the degree of crystallinity and melting temperature $\left(\mathrm{T}_{\mathrm{m}}\right)$ of the material.

Compression tests were conducted across a range of strain rates from quasi-static to dynamic. Low rate tests were performed with an Instron model 1331 servo-hydraulic load frame. Load was measured with an Instron 311 
G-135 load cell, and specimen strain was inferred from a linear variable differential transformer (LVDT) measurement of crosshead displacement, using a correction for machine compliance. The cylindrical specimens for these experiments were nominally $5 \mathrm{~mm}$ in diameter and length. Contact surfaces between the specimens and the tungsten carbide platens were lubricated with $\mathrm{MoS}_{2}$ grease to minimize resistance to radial expansion during compression. High temperature experiments were performed using the same load frame and a temperature-controlled chamber (Instron Model 3119-405). The chamber thermocouple feedback control measurement was used to determine specimen temperature. The temperature of the specimen was allowed to equilibrate with the chamber for $30 \mathrm{~min}$ prior to starting the compression test.

High strain rate tests were performed with a $9.525 \mathrm{~mm}$ diameter 7075-T6 aluminum split Hopkinson pressure bar (SHPB), with the details of the apparatus provided in Refs. [18-20]. The cylindrical samples were nominally $5 \mathrm{~mm}$ in diameter and length. They were lubricated with $\mathrm{MoS}_{2}$ grease to ensure free radial expansion. Elevated temperature tests were performed by placing a custom, temperature-controlled chamber around the specimen and adjacent $75 \mathrm{~mm}$ sections of the incident and transmitted bars. Hot air was circulated through the chamber for $20 \mathrm{~min}$ prior to testing. The temperature inside the chamber was monitored with a Keithley thermocouple reader model 871 with a K-type thermocouple affixed to the bar at the specimen-bar interface. Note that the entire length of the bars was not heated during the test; the modest temperature gradients established in the bars were determined to have a negligible effect on the results through comparison between free end bar response with and without heating. The SHPB analysis used a correction for bar wave dispersion [21-23]. Equilibrium in the samples was confirmed by comparison of one-wave and two-wave stresses.

Taylor tests [24-26] were conducted on nominally $25.4 \mathrm{~mm}$ long samples with a diameter of $6.3 \mathrm{~mm}$. The cylinders were fired in air without a sabot from a $6.43 \mathrm{~mm}$ barrel into a 350 Maraging steel anvil polished to a $1 \mu \mathrm{m}$ finish at velocities ranging $125-200 \mathrm{~m} / \mathrm{s}$. The impact surface of the anvil was lubricated with grease to minimize friction during impact. A Shimadzu HyperVision HVP-X high speed video camera was used to capture the in situ deformation. The 25616 bit greyscale images were taken with at 500,000 frames per second with a $400 \mathrm{~ns}$ exposure time. The images were manually analyzed post-test ImageJ image processing software. After the stack of 256 images was imported, a timestamp label was added and the brightness and size of the image stack was adjusted for maximum clarity. The scale was set using a grid placed behind the sample plane, where the horizontal spacing is equal to $3.91 \mathrm{~mm}$. For each image, the following data points, as defined by Brown et al. [8], were measured manually: maximum width of the primary deformation zone $\left(d_{0}\right)$, maximum width of the secondary deformation zone $\left(d_{x}\right)$, width of the undeformed region $(d)$, length of the entire sample $(L)$, length of the secondary deformation zone plus the undeformed region $\left(L_{x}\right)$, length of the undeformed region $\left(L_{0}\right)$. The measurements were accurate to a pixel, which corresponds to $0.11 \mathrm{~mm}$. There are several minor sources of error in these experiments. An experimental artifact, approximately $16 \mathrm{~mm}$ in diameter, was present in the lower right area of the images, which adds 2-3 pixel possible error to some of the $d_{x}$ measurements. Additionally, extrusion of the thin layer of grease present on the anvil occurred in some images, which could add 2-3 pixel error to the length measurement when the sample is almost in contact with the steel anvil. Finally, on select images, the shadow of the sample overlaps the bottom edge of the impact face, adding 2-3 pixels of error to the measured value of $d_{0}$. Using the grid behind the sample results in a systematic error in the conversion from pixels to millimeters, typically equivalent to approximately $1 \mathrm{~mm}$ across the total length of the sample, since the grid was not in the plane of the experiment but was displaced several centimeters behind the test.

\section{Results and Discussion}

The differential scanning calorimetry results are shown in Fig. 1. The melting temperature seen as the peak at $109^{\circ} \mathrm{C}$ is much less than that reported for $\operatorname{HDPE}\left(134^{\circ} \mathrm{C}\right)$ and UHMWPE and PEX $\left(133{ }^{\circ} \mathrm{C}\right)[6]$, but in good agreement with that reported for LDPE [16]. The area under the DSC

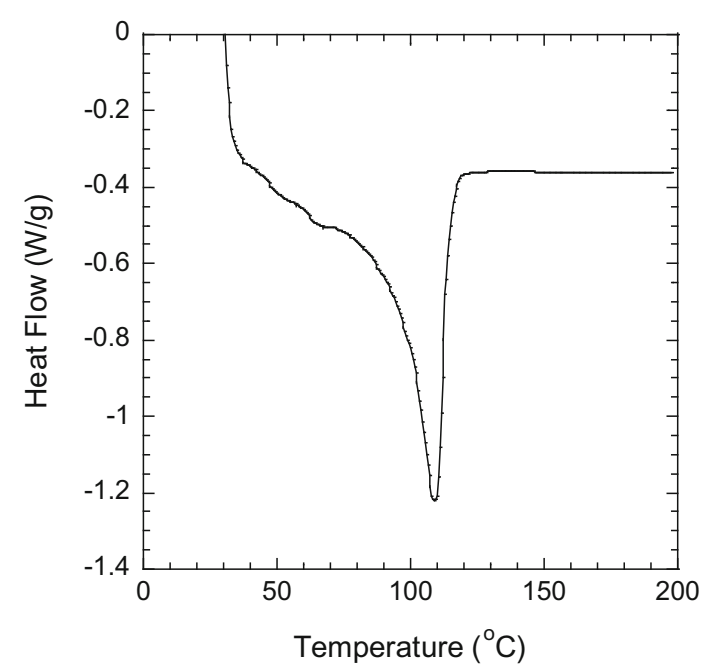

Fig. 1 Differential scanning calorimetry for LDPE showing a melting temperature of $109{ }^{\circ} \mathrm{C}$ 
melt endotherm corresponds to the heat of melt equal to 111.7 J/g for this LDPE. Using the heat of melt for a perfect PE crystal to be $288.84 \mathrm{~J} / \mathrm{g}$, the percent crystallinity for this LDPE is $38.7 \%$, which is similar to the UHMWPE and PEX studied by Brown et al. [6] but significantly less than the HDPE in the same study [6].

The stress-strain response of LDPE across a range of strain rates is shown in Fig. 2 and temperatures in Fig. 3, where the varying temperature measurements were conducted at two different strain rates. The stress-strain curve shows an initial linear elastic region followed by a nonlinear transition to global yield, which is followed by strain softening and then strain hardening. As expected in most polymers, LDPE shows an increase in stress with increasing strain rate or decreasing temperature. The qualitative stress-strain response of the LDPE is very similar to that seen by Brown et al. for UHMWPE and PEX [6], which may be expected due to the similar crystalline volume fractions, and by Omar et al. for LDPE [16]. The actual strength values at low strain rates for the LDPE in this study are higher than those measured by Omar et al. [16], which is to be expected since the degree of crystallinity is higher in our LDPE. Omar et al. [16] observed a steep increase in stress as a function of strain rate at dynamic strain rates; however, this was not observed in our data or that presented by Brown et al. [6].

In order to compare the data on LDPE from this study with data on other polyethylene conformations [6], the true stress at $7.5 \%$ (closed symbols and solid lines) and $20 \%$ strain (open symbols and dashed lines) is plotted versus strain rate in Fig. 4. The strain rate dependence in LDPE can be captured with a simple logarithmic fit:

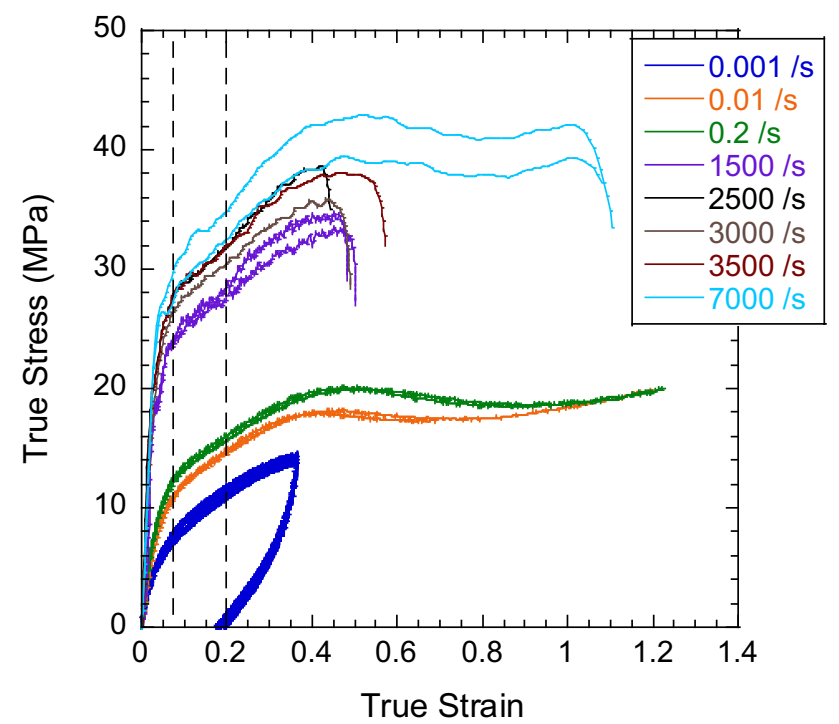

Fig. 2 Stress-strain response of LDPE across a range of strain rates at room temperature
$\sigma=D+E \log (\dot{\varepsilon})$

where $\sigma$ is the true stress at a given strain, $\dot{\varepsilon}$ is the strain rate, and $D$ and $E$ are the intercept and slope, respectively. Although there is no experimental data available in the intermediate strain rates $(1-100 / \mathrm{s})$, the same linear trend observed in UHMWPE and PEX [6] is expected, which varies from trends observed in other semi-crystalline polymers such as PTFE which exhibits a bilinear dependence on strain rate [27, 28].

The dependence of true stress at 7.5 and $20 \%$ strain as a function of temperature is shown in Fig. 5 at quasi-static $(0.001 / \mathrm{s})$ and dynamic $(3000 / \mathrm{s})$ strain rates. The temperature dependence can be fit with

$\sigma=B+C \times T$

where $T$ is the temperature and $B$ and $C$ are the intercept and slope respectively. The fits to Eqs. 1 and 2 for LDPE at $7.5 \%$ strain are shown in Table 2. The fits at $20 \%$ strain had nominally the same slope, $C$ and $E$, with the intercept, $B$ and $D$, offset for the value at increased strain. As noted by Brown et al. [6], when the flow stress is plotted as a function of temperature, most polymers exhibit three semi-linear regimes: (I) a glassy regime at low temperatures with minimal negative slope, (II) a transition regime with a very steep negative slope, and (III) a rubbery regime at high temperatures with a modest negative slope. The value of $T_{g}$ is commonly defined as the midpoint of region II. This is manifested as a bi-linear dependence of flow stress on temperature and log strain rate for most polymers. For HDPE, UHMWPE, and PEX, a single linear relation was observed by Brown et al. [6] for the full range of temperatures and strain rates investigated. The current work shows that the single linear relation to temperature and log strain rate applies to LDPE, as well.

Siviour et al. [29] proposed a mapping between temperature and strain rate using a single mapping parameter, A, based on the time-temperature superposition of polymers:

$T=T_{0}+A\left(\log \dot{\varepsilon}_{0}-\log \dot{\varepsilon}\right)$

where the subscript 0 corresponds to a reference temperature and strain rate. The mapping parameter, $A$, can be determined from fitting to experimental data. Due to the apparent lack of thermal transitions in LDPE, similar to other PE conformations, this single parameter fit should accurately capture the temperature and strain rate dependent behavior. From Brown et al. [6], the mapping parameter $A$ is related to the fitting parameters $B, C, D$, and $E$ according to:

$A=-\frac{E}{C} \frac{\sigma-(20 C+B)}{\sigma-(D-3 E)}$

where the reference experimental temperature is $20{ }^{\circ} \mathrm{C}$ and the reference experimental strain rate is $0.001 / \mathrm{s}$. The equation has been modified to take into account the 


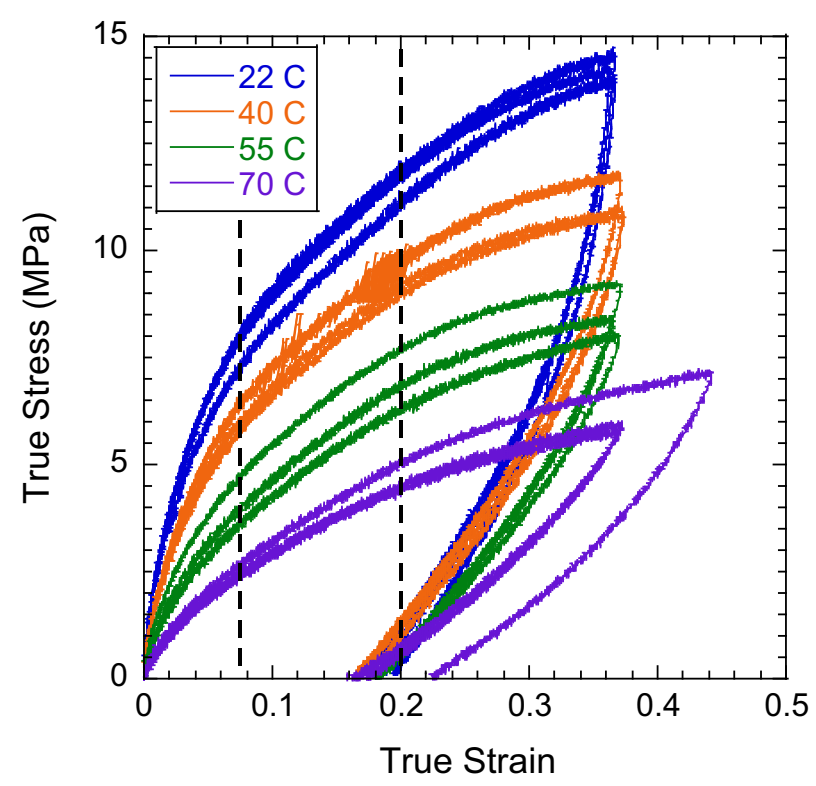

(a)

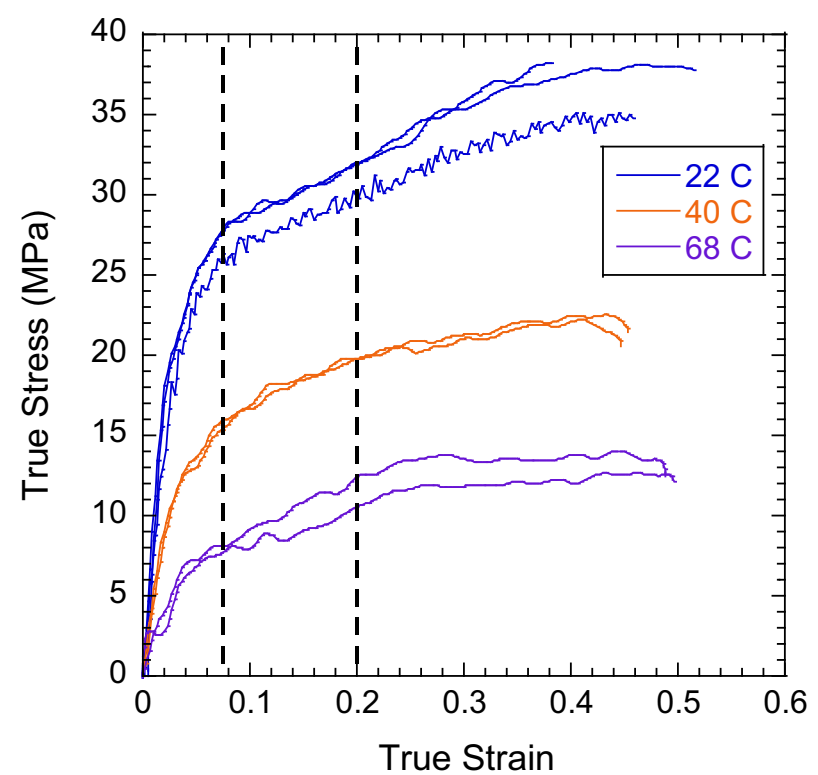

(b)

Fig. 3 Stress-strain response of LDPE across a range of temperatures at a 0.01/s and b 3000/s

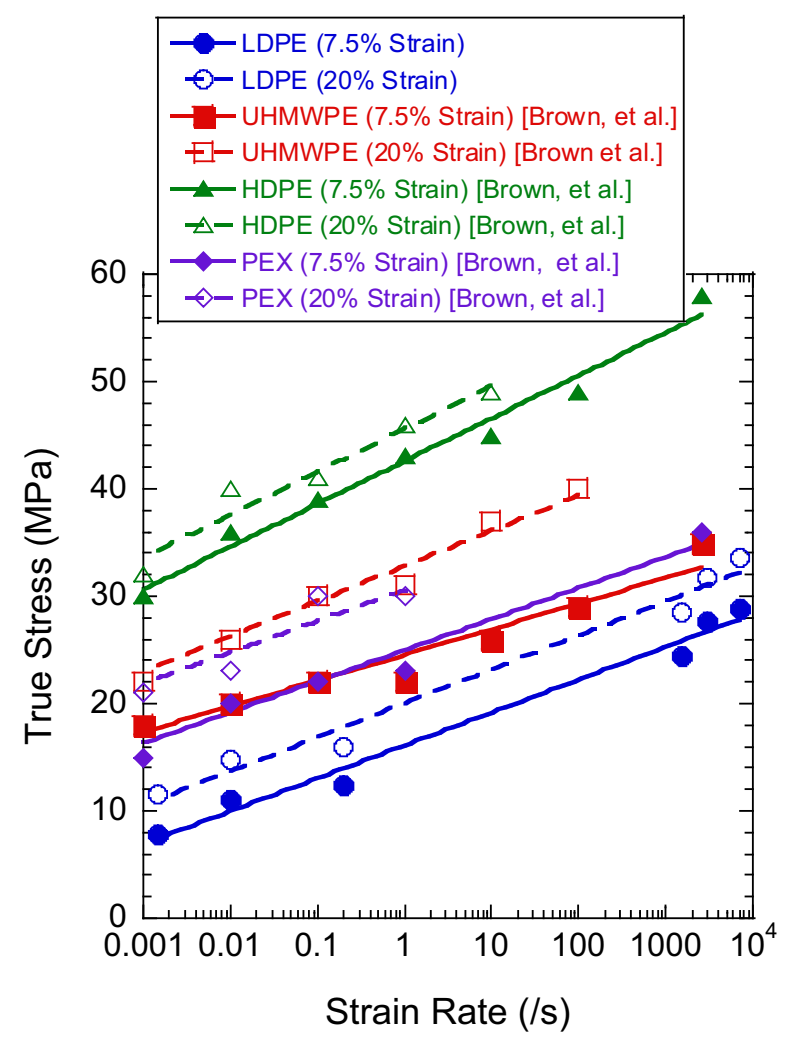

Fig. 4 Stress at $7.5 \%$ strain (closed symbols and solid lines) and $20 \%$ strain (open symbols and dashed lines) for LDPE compared with UHMWPE, HDPE, and PEX [6]

different reference strain rates between this study and that conducted by Brown et al. [6]. From Eq. 4, it can be seen that $A$ will be a unique value if and only if [6]:

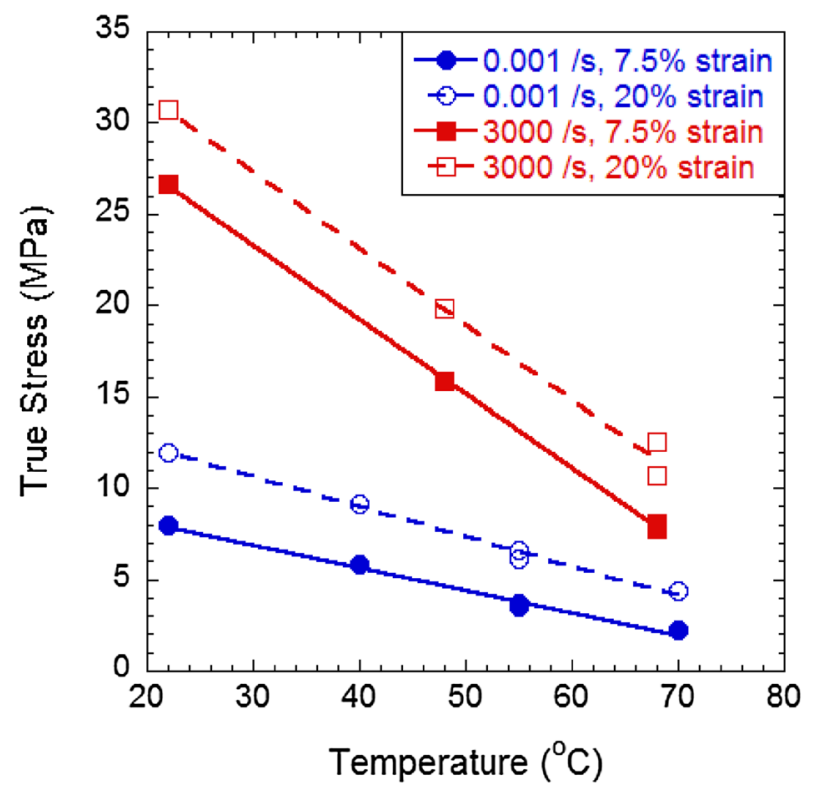

Fig. 5 True stress versus temperature at quasi-static and dynamic strain rates in LDPE

$B+20 C=D-3 E$

which is equivalent to saying that Eqs. 1 and 2 must generate a single common point at their intersection. If the condition in Eq. 5 is met, then:

$A \equiv-E / C$

regardless of the reference strain rate and temperature. For LDPE, Eq. 6 results in $A=24.5^{\circ} \mathrm{C}^{*} \log (\mathrm{s})$. However, 
Table 2 Fits to Eqs. 1 and 2 for LDPE at $7.5 \%$ strain

\begin{tabular}{lcccc}
\hline & LDPE current study & HDPE [6] & UHMWPE [6] & PEX [6] \\
\hline B $(\mathrm{MPa})$ & 10.636 & 44.681 & 26.095 & 26.791 \\
$\mathrm{C}\left(\mathrm{MPa} /{ }^{\circ} \mathrm{C}\right)$ & -0.1238 & -0.3816 & -0.2214 & -0.2359 \\
$\mathrm{D}(\mathrm{MPa})$ & 16.37 & 42.74 & 24.77 & 25.69 \\
$\mathrm{E}[\mathrm{MPa} * \log (\mathrm{s})]$ & 2.9944 & 3.9125 & 2.3516 & 3.0319 \\
\hline
\end{tabular}

The temperature dependent fit from Eq. 2 is taken from the quasi-static data since Eqs. 1 and 2 do not predict a unique intersection at $\dot{\varepsilon}=0.001 \mathrm{~s}^{-1}$ and $T=20{ }^{\circ} \mathrm{C}$, then Eq. 6 is not rigorously satisfied resulting in a deviation from the equality in Eq. 5, which for LDPE is 1.08, which is in agreement with those determined for similar PE materials by Brown et al. [6]. For comparison, reported values of $A$ for other polymers are $10.28,10.62,12.87^{\circ} \mathrm{C}^{*} \log (\mathrm{s})$ for HDPE, UHMWPE, and PEX, respectively [6], and $17^{\circ} \mathrm{C}^{*} \log (\mathrm{s})$ for both polycarbonate and PVDF [29], and $8{ }^{\circ} \mathrm{C} * \log (\mathrm{s})$ for PTFE [27].

The calculated value of $A$ is used to map the strain rate and temperature dependent data shown in Figs. 4 and 5 to a single strain rate equal to $0.001 \mathrm{~s}^{-1}$ in Fig. 6. Generally, there is good agreement with the mapped data and that tested at the reference strain rate with varying temperature. The major discrepancy arises from the data that was tested at high strain rate with varying temperature, which was not used to fit Eq. 1 or 2. It can be seen that the slopes of the lines fitting the temperature dependent data in Fig. 5 at low and high strain rates are not parallel as would be expected if a single parameter was adequate to map all the data. This may indicate that a second temperature or rate dependent

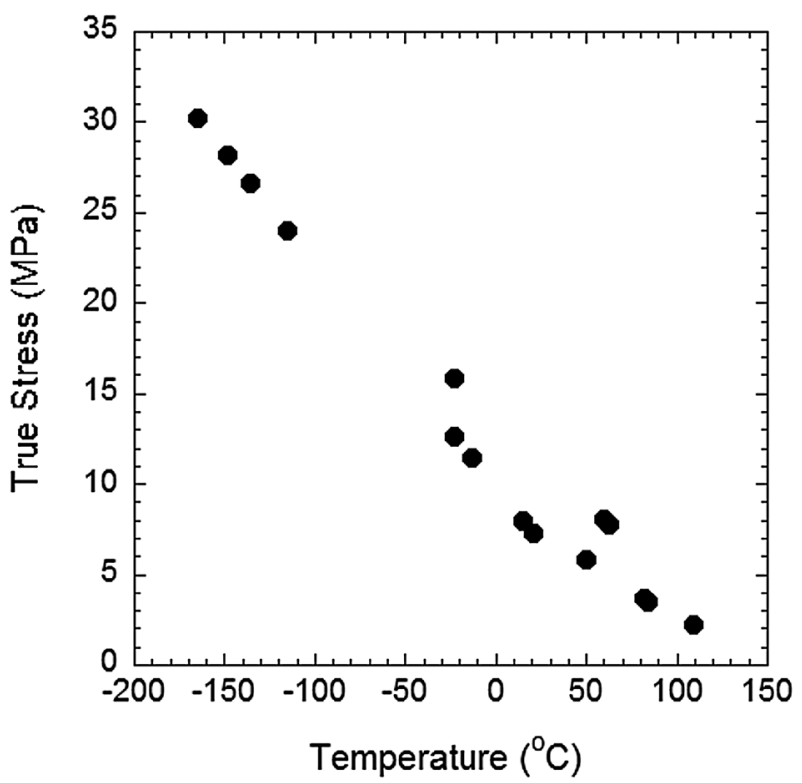

Fig. 6 Mapping of true stress at $7.5 \%$ strain for LDPE from Figs. 4 and 5 to $0.001 \mathrm{~s}^{-1}$ mechanism is contributing to the data, particularly at high strain rate.

Eight Taylor test experiments were conducted at impact velocities ranging from 125 to $196 \mathrm{~m} / \mathrm{s}$, as shown in Fig. 7 . It can be seen that at all velocities that the LDPE deforms with a primary deformation zone near the anvil, a secondary deformation zone, and an undeformed zone at the end. The three lengths and diameters shown in Fig. 7 were extracted throughout the experiment and are shown for the lowest and highest impact velocities in Fig. 8. Similar to the work by Brown et al. [8] on other forms of PE, the length of the primary compression zone $\left(L-L_{x}\right)$ reaches its maximum length within the first $20-30 \mu$ s and then remains constant for the duration of the measured loading. As expected, the higher impact velocity experiment has a greater compression, smaller minimum $L_{0}$, than the lower velocity impact experiment. Correspondingly, the maximum diameter of the primary deformation zone, $d_{0}$, is larger in the higher velocity experiment. In all of the experiments, the samples exhibited a rapid increase to maximum compression followed by recovery, where the length increases, which is attributed to viscoelastic-viscoplastic behavior and has been observed in other polymer materials $[8,30]$.

In the previous work investigating HDPE, UHMWPE, and PEX, the responses of UHMWPE and PEX were very similar while exhibiting significant differences from HDPE [6]. The HDPE samples exhibit higher yield stress followed by a flow behavior that is flat to first order. Conversely, UHMWPE and PEX both exhibit strain hardening after yield. However, since their yield stress is significantly lower than HDPE, they do not reach the flow stress level of HDPE until between 40 and $50 \%$ true strain. In the current work, LDPE appears to have a similar strain hardening behavior after yield as the UHMWPE and PEX, although without a bilinearity in flow behavior observed for UHMWPE and PEX with the hardening rate, i.e. slope, increasing above $15 \%$ true strain. Under Taylor testing, UHMWPE and PEX were previously seen to exhibit similar responses with a distinct difference from HDPE. The profile can be divided into three unique zones: a primary deformation zone (at the impact face), a secondary deformation zone (in the middle), and an undeformed zone (at the free end). Qualitatively, the primary deformation zone 


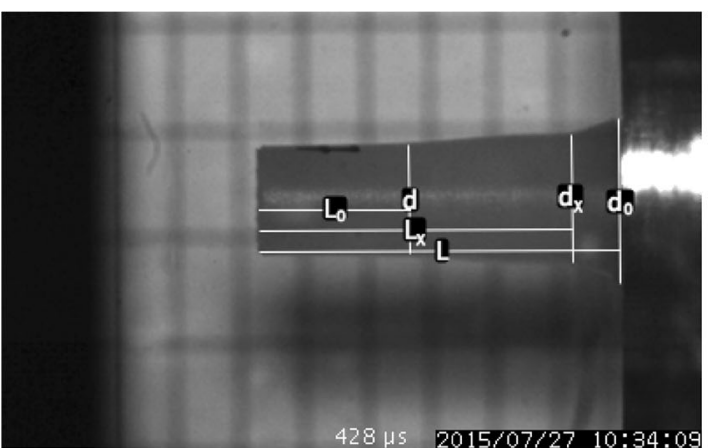

(a)

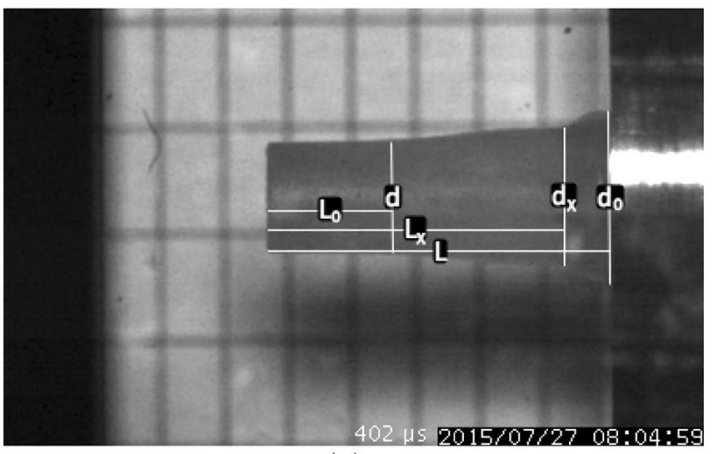

(c)

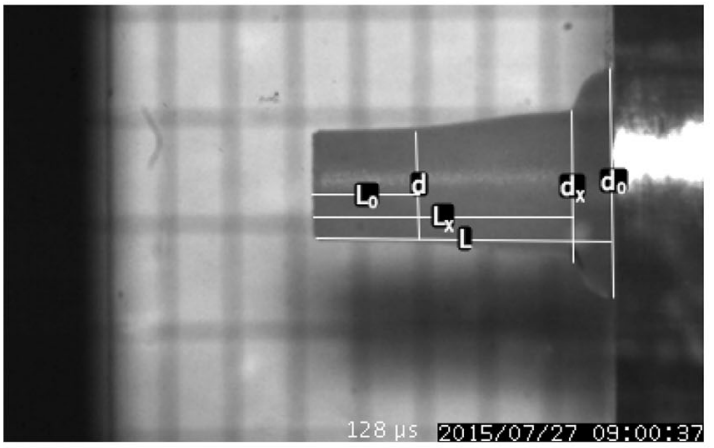

(e)

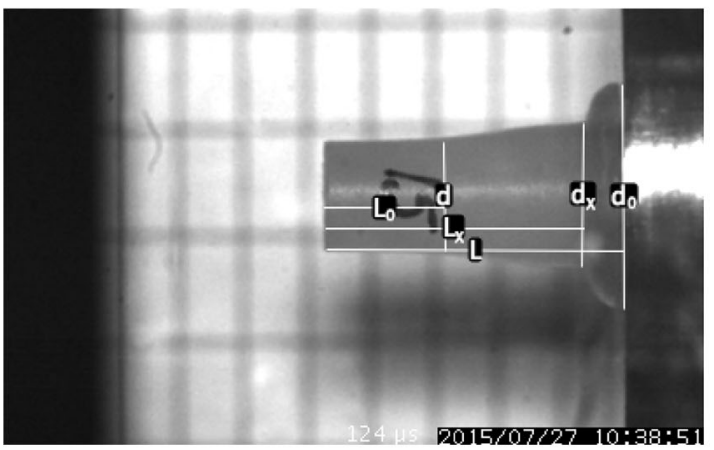

(g)

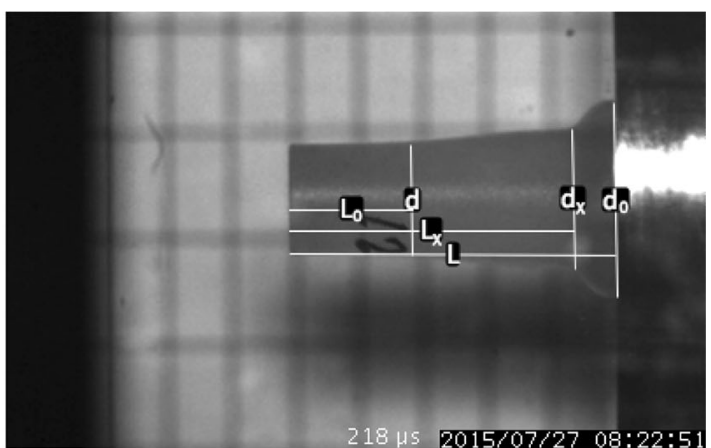

(b)

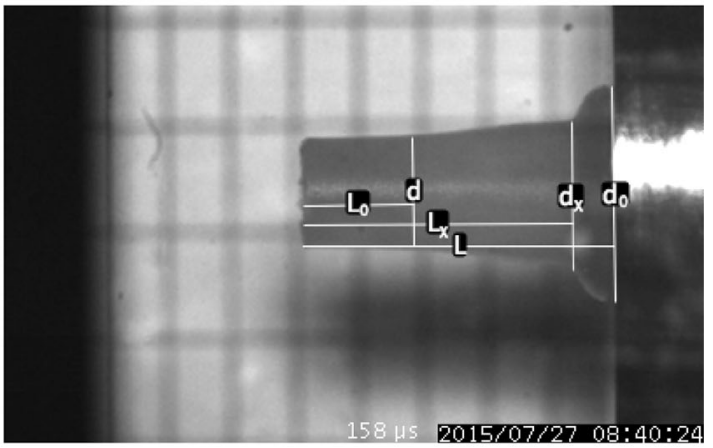

(d)

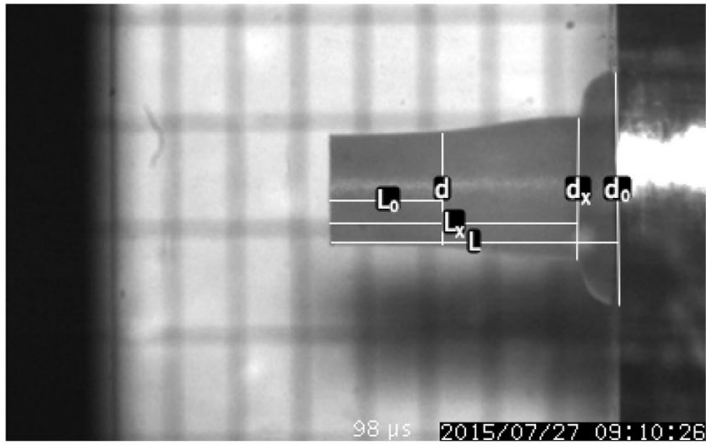

(f)

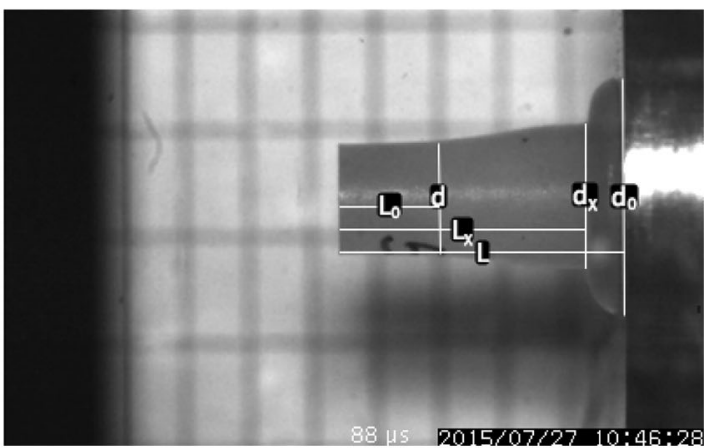

(h)

Fig. 7 Taylor impact experiments at maximum compression for a $125 \mathrm{~m} / \mathrm{s}, \mathbf{b} 149 \mathrm{~m} / \mathrm{s}, \mathbf{c} 151 \mathrm{~m} / \mathrm{s}, \mathbf{d ~} 168 \mathrm{~m} / \mathrm{s}, \mathbf{e} 185 \mathrm{~m} / \mathrm{s}, \mathbf{f} 194 \mathrm{~m} / \mathrm{s}, \mathbf{g ~} 195 \mathrm{~m} / \mathrm{s}$, and $\mathbf{h} 196 \mathrm{~m} / \mathrm{s}$

$\left(L-L_{x}\right)$ was consistent between HDPE, UHMWPE, and PEX ( $\sim 8 \%$ of the initial rod length), but appears larger in the softer LDPE ( $\sim 11 \%$ of initial rod length). The length of the secondary deformation zone $\left(L_{x}-L_{0}\right)$ was much longer in UHMWPE and PEX where it spanned nearly half the initial rod length while in HDPE it only spanned about 


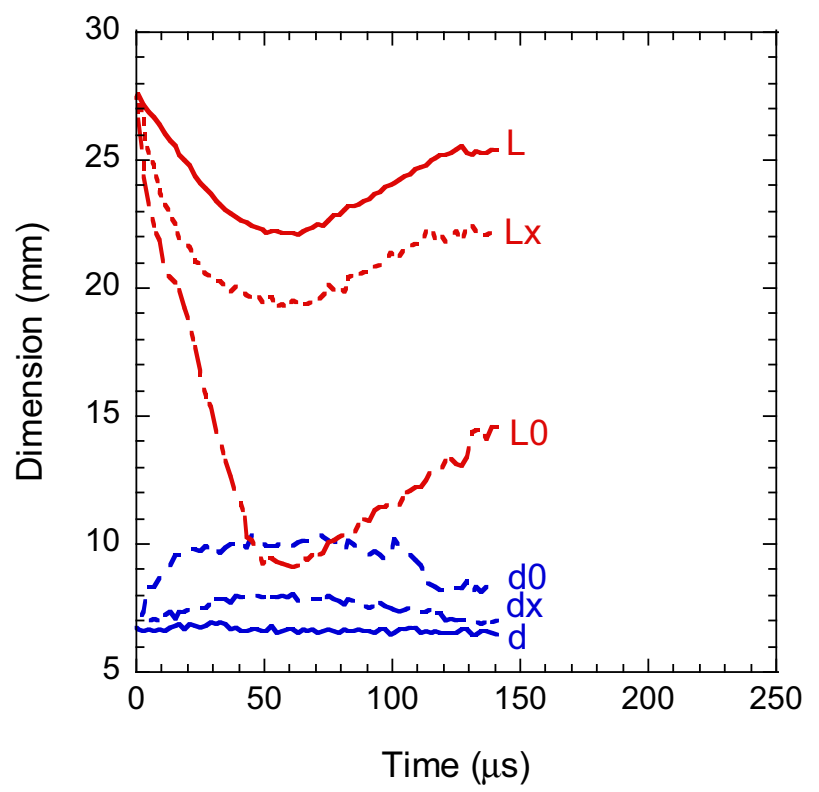

(a)

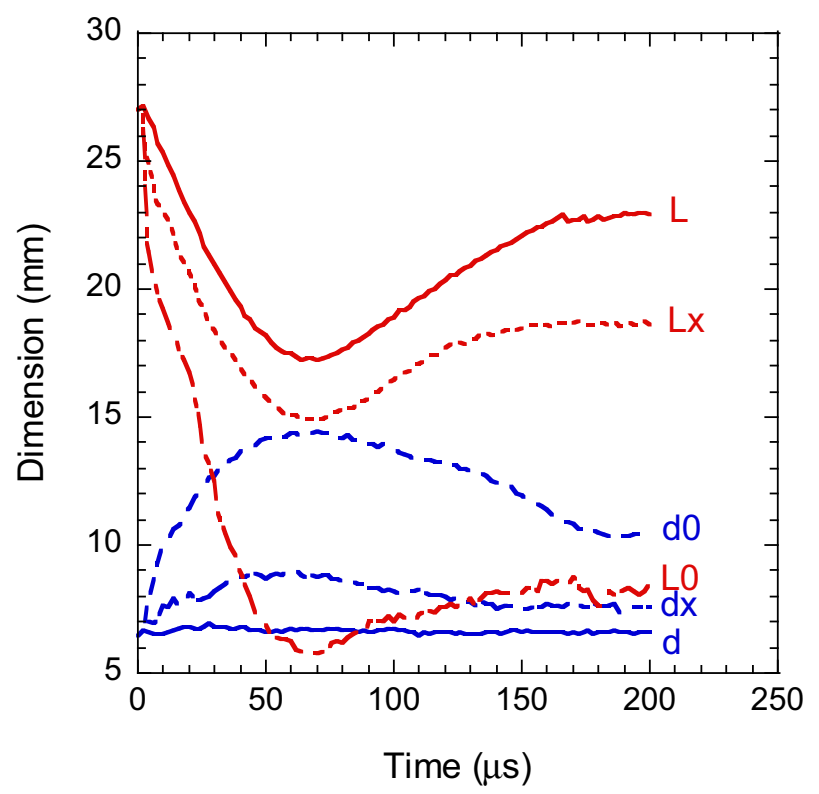

(b)

Fig. 8 Taylor test sample profile as a function of time for a $125 \mathrm{~m} / \mathrm{s}$ and b $196 \mathrm{~m} / \mathrm{s}$

a quarter of the initial rod length. In LDPE, this region spans about a third of the initial rod length. The diameter of the secondary deformation zone is consistent between forms of PE and reaches its maximum length early in the test. However, the diameter of the primary deformation zone was much larger $(\sim 30 \%)$ in HDPE than in UHMWPE and PEX. In the current work, the evolution of both $D_{x}$ and $D_{0}$ appear more consistent with HDPE than UHMWPE and PEX. The diameter of the free rod end does not change from the initial diameter over the course of the test for any forms of PE. It should be pointed out that the complex deformation of the rod for HDPE can be captured by finite element modeling when extrapolating quasistatic and SHPB data $[10,12]$. The maximum compression as a function of impact velocity is shown in Fig. 9. LDPE exhibits a linear behavior, which is more consistent with that of UHMWPE and PEX than HDPE [8] and is consistent with the results of the compression tests discussed above.

The nominal strain rate for a Taylor impact experiment can be estimated by:

$\dot{\varepsilon} \approx \frac{U}{2\left(L_{\text {initial }}-L_{0}\right)}$

where $U$ is the impact velocity [26]. The nominal strain rate in LDPE for the range of impact velocities was between 3500 and $4600 \mathrm{~s}^{-1}$, which is at the upper range of the strain rates tested using SHPB. Figure 10 shows the comparison of the yield strength calculated using the stress level at $7.5 \%$ strain extrapolated to the calculated strain

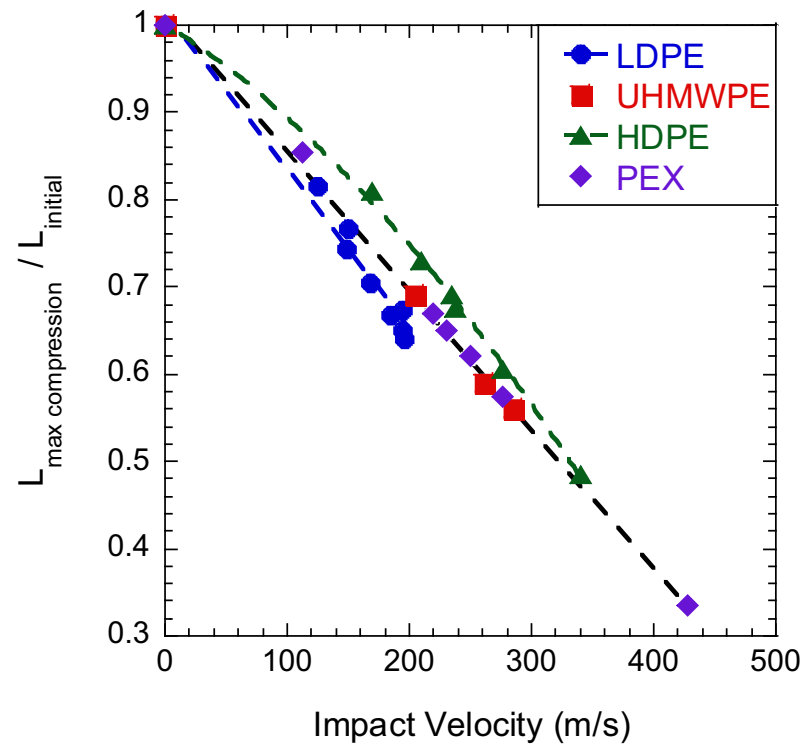

Fig. 9 Ratio of maximum compression length to initial length as a function of impact velocity for LDPE in comparison to UHMWPE, HDPE, and PEX [8]

rate for the Taylor test in comparison with that calculated using Taylor's theory [25]. Interestingly, the theory, which was developed for metals, shows reasonable agreement with the experimental data, which was also true for the HDPE, PEX, and UHMWPE materials studied previously [8]. This agreement indicates that the log linear relationship with strain rate is maintained at strain rates higher than those achievable in the SHPB. 


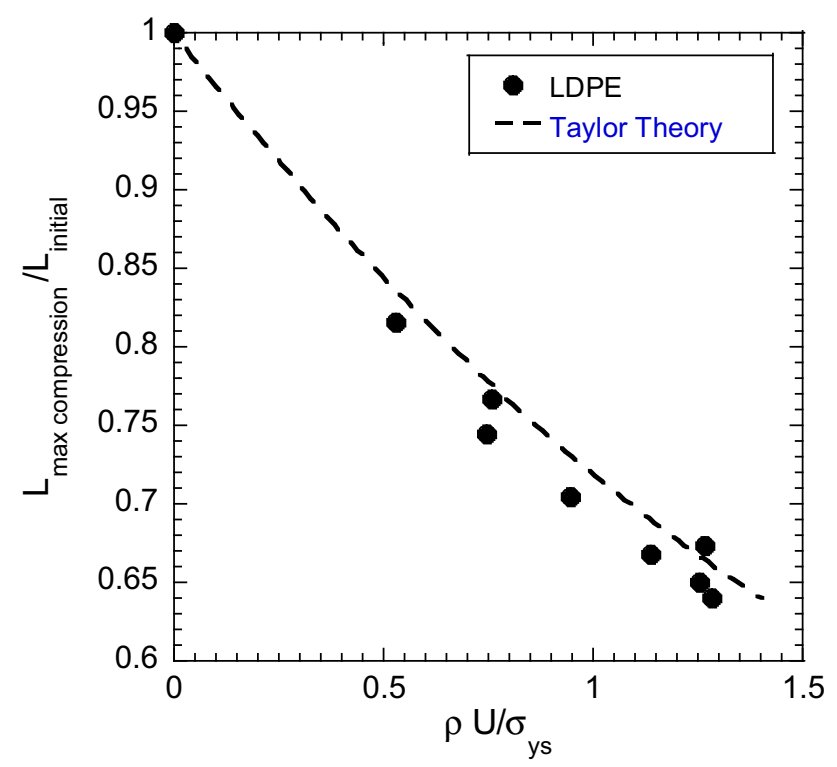

Fig. 10 Ratio of maximum compression length to initial length as a function of $\rho U / \sigma_{y s}$ for LDPE, where $\rho$ is the density, $U$ is the impact velocity, and $\sigma_{y s}$ is the yield strength

\section{Conclusions}

The compressive response of low density polyethylene (LDPE) was investigated across a range of strain rates and temperatures. The mechanical response was found to be temperature and strain rate dependent, showing an increase in stress with increasing strain rate or decreasing temperature. The response of LDPE was found to be very similar to the response of UHMWPE and PEX [6, 8] and the stress-strain response was qualitatively similar to the response of LDPE tested by Omar et al. [16], where the quantitative difference is attributed to the difference in crystallinity between the two materials tested. Interestingly, Omar et al. [16] observed a non-linear increase in stress with $\log$ strain rate, albeit based on data at a limited number of strain rates, which was not observed in either the materials in this study or the materials studied by Brown et al. $[6,8]$. The temperature and strain rate data were mapped using the method developed by Siviour et al. [29] based on time-temperature superposition using a single mapping parameter indicating that there are no structural transitions over the rates and temperatures investigated. Taylor impact experiments were conducted showing a double deformation zone and yield strength measurements in agreement with compression experiments.

Acknowledgments The authors would like to thank the Army Research Laboratory and Air Force Office of Scientific Research for supporting this work.

\section{References}

1. Vasile C, Pascu M (2005) Practical guide to polyethylene. Rapra Technologies, LTD., Shawbury

2. Hiss R, Hobeika S, Lynn C, Strobl G (1999) Network stretching, slip processes, and fragmentation of crystallites during uniaxial drawing of polyethylene and related copolymers: a comparative study. Macromolecules 32(13):4390-4403

3. Hobeika S, Men Y, Strobl G (2000) Temperature and strain rate independence of critical strains in polyethylene and poly(ethylene-co-vinyl acetate). Macromolecules 33(5):1827-1833

4. Schrauwen BAG, Janssen RPM, Govaert LE, Meijer HEH (2004) Intrinsic deformation behavior of semicrystalline polymers. Macromolecules 37(16):6069-6078

5. Bartczak Z, Kozanecki M (2005) Influence of molecular parameters on high-strain deformation of polyethylene in the planestrain compression. Part I. Stress-strain behavior. Polymer 46(19):8210-8221

6. Brown EN, Willms RB, Gray GT III, Rae PJ, Cady CM, Vecchio KS, Flowers J, Martinez MY (2007) Influence of molecular conformation on the constitutive response of polyethylene: a comparison of HDPE, UHMWPE, and PEX. Exp Mech 47(3):381-393

7. Siviour CR, Jordan JL (2016) High strain rate mechanics of polymers: a review. J Dynam Behav Mater 2(1):15-32

8. Brown EN, Trujillo CP, Gray GT (2007) Influence of Polyethylene molecular conformation on taylor impact measurements: a comparison of HDPE, UHMPE, and PEX. AIP Conf Proc 955(1):691-694

9. Furmanski J, Brown EN, Clements B, Cady CM, Gray Iii GT (2012) Large-strain time-temperature equivalence in high density polyethylene for prediction of extreme deformation and damage. In: EPJ Web of Conferences

10. Furmanski J, Cady CM, Brown EN (2013) Time-temperature equivalence and adiabatic heating at large strains in high density polyethylene and ultrahigh molecular weight polyethylene. Polymer 54(1):381-390

11. Millett JCF, Brown EN, Gray GT, Bourne NK, Wood DC, Appleby-Thomas G (2016) The effects of changing chemistry on the shock response of basic polymers. J Dynam Behav Mater 2(3):326-336. doi:10.1007/s40870-016-0068-0

12. Furmanski J, Trujillo CP, Martinez DT, Gray GT III, Brown EN (2012) Dynamic-tensile-extrusion for investigating large strain and high strain rate behavior of polymers. Polym Test 31(8):1031-1037

13. Brown E, Furmanski J, Ramos K, Dattelbaum D, Jensen B, Iverson A, Carlson C, Fezzaa K, Gray G III, Patterson B (2014) High-density polyethylene damage at extreme tensile conditions. J Phys: Conf Ser 500:112011

14. Rae P, Brown E (2015) Some observations on measuring sound speeds in polymers using time-of-flight. Exp Techn. doi:10.1111/ ext.12163

15. Bourne N, Millett J, Brown E, Gray G III (2007) Effect of halogenation on the shock properties of semicrystalline thermoplastics. J Appl Phys 102(6):063510

16. Omar MF, Akil HM, Ahmad ZA (2012) Effect of molecular structures on dynamic compression properties of polyethylene. Mater Sci Eng A 538:125-134

17. Nakai K, Yokoyama T (2015) Uniaxial compressive response and constitutive modeling of selected polymers over a wide range of strain rates. J Dynam Behav Mater 1(1):15-27

18. Gray GT (2000) Classic split-Hopkinson pressure bar testing. ASM International, Materials Park, pp 462-476 
19. Gray GT, Blumenthal WR (2000) Split-Hopkinson pressure bar testing of soft materials. ASM International, Materials Park, pp 488-496

20. Chen WW (2016) Experimental methods for characterizing dynamic response of soft materials. J Dynam Behav Mater 2:2-14

21. Gorham D (1983) A numerical method for the correction of dispersion in pressure bar signals. J Phys E: Sci Instrum 16(6):477-479

22. Follansbee PS, Franz C (1983) Wave propagation in the splitHopkinson pressure bar. J Eng Mater Technol 105:61

23. Gong JC, Malvern LE, Jenkins DA (1990) dispersion investigation in the split Hopkinson pressure Bar. J Eng Mater Technol 112:309-314

24. Taylor G (1946) James Forrest Lecture 1946. The testing of materials at high rates of loading. J Inst Civ Eng 26(8):486-519

25. Taylor G (1038) The use of flat-ended projectiles for determining dynamic yield stress. I. Theoretical considerations. Proc R Soc Lond A: Math Phys Eng Sci 1948(194):289-299
26. Hutchings I (1978) Estimation of yield stress in polymers at high strain-rates using GI Taylor's impact technique. J Mech Phys Solids 26(5):289-301

27. Jordan JL, Siviour CR, Foley JR, Brown EN (2007) Compressive properties of extruded polytetrafluoroethylene. Polymer 48(14):4184-4195

28. Walley S, Field J (1994) Strain rate sensitivity of polymers in compression from low to high rates. DYMAT J 1(3):211-227

29. Siviour CR, Walley SM, Proud WG, Field JE (2005) The high strain rate compressive behaviour of polycarbonate and polyvinylidene difluoride. Polymer 46(26):12546-12555

30. Ferranti L Jr, Thadhani NN (2007) Dynamic mechanical behavior characterization of epoxy-cast $\mathrm{Al}+\mathrm{Fe}_{2} \mathrm{O}_{3}$ thermite mixture composites. Metall Mater Trans A 38(11):2697-2715 